\title{
Competitive Strategies and Financial Performance: The Impact of Scope and Competitive Weapons
}

\author{
Julio O. DeCastro \\ University of Colorado \\ Boulder, Colorado \\ James J. Chrisman \\ University of Calgary \\ Calgary, Alberta \\ Canada \\ David M. Schweiger \\ William R. Sandberg \\ University of South Carolina \\ Columbia, South Carolina
}

\section{Introduction}

A business's competitive strategy defines the match it makes between its environment and resources in pursuit of its objectives (Hofer and Schendel 1978). In keeping with this definition, two primary components, scope and competitive weapons, have been used to describe competitive strategies (Chrisman, Hofer, and Boulton 1988; Porter 1980). Scope describes the environment a firm serves and can be classified as broad or narrow (Abell 1980; Chrisman, et al. 1988; Porter 1980). Competitive weapons describe the ways a firm uses its resources to create a competitive advantage (Chrisman, et al. 1988; Hofer and Schendel 1978). Achieving a low delivered cost position or product differentiation are the two primary competitive weapons from which firms may chose (Porter 1980). When a firm achieves both low cost and differentiation it is said to utilize "utility" weapons (Chrisman, et al. 1988). However, not all firms are able to develop low cost and/or differentiated positions. Porter (1980) has labeled these unfortunate firms "stuck-in-the-middle" because they lack a basis for competitive advantage.

Despite much attention in the literature to the impact of strategy on firm performance, the effects of a firm's scope and competitive weapons are notably unclear in the cases of strategies characterized by narrow scope or utility weapons (Chrisman, et al. 1988). To help resolve this ambiguity, this study investigates the impact of competitive strategy, measured in terms of scope and competitive weapons, on the performance of a sample of business units competing in mature, concentrated, manufacturing industries producing heterogeneous products for domestic markets.

\section{Conceptual Model}

The conceptual model for this study is based on the notion that among businesses in similar environments, performance will be a function of competitive strategy. In turn, a 
business's competitive strategy can be described in terms of its scope and competitive weapons. This basic conceptual model is depicted in the functional relationship shown below.

$$
\text { Business Performance }=\mathrm{f}(\text { Scope }, \text { Competitive Weapons })
$$

In the following pages we elaborate on the concepts of scope and competitive weapons and also discuss how the interaction of strategic decisions in these two areas influences the financial performance of a business.

\section{The Concept of Scope}

At the business level, scope is defined as the extent of a firm's product-market domain in one specific industry (Abell 1980; Hofer and Schendel 1978; Porter 1980). Operationalizations of scope have typically distinguished between firms that choose to compete in most or all of the major product-market segments in an industry (broad scope) and those which restrict their domain to one or a few smaller segments (Abell 1980; Chrisman, et al. 1988; Porter 1980). However, our understanding of scope is limited. Thus, White (1986) chose not to include focused strategies in his study of generic strategies, organizational characteristics, and performance because of a lack of previous conceptualizations of the organizational characteristics associated with narrow scope. Furthermore, while broad and narrow scope firms appear to be different in their fundamental characteristics (Murray 1988), the limited research comparing their performance has been inconclusive. For example, Miller (1991) argued that scope may be a source of competitive advantage but found no significant relationships between scope and performance.

Firms with broad scopes may enjoy, among others, two primary advantages that are less readily available to firms with narrow scopes: economies of scale and economies of scope. Economies of scale occur when the unit costs of a product decline as the volume produced and sold increases (Porter 1980). Such economies enable a firm to supply a product at a lower cost than several smaller firms producing and selling the same cumulative volume (Carroll 1984). In the main, firms competing in a broad array of market segments should be better positioned to exploit scale economies than firms competing in a more limited domain. A larger base of customers usually leads to higher sales volumes, more efficient capital-intensive production techniques, and lower research and development expenditures per unit. Since economies of scale are positively related to firm performance (Capon, Farley, and Hoeing 1990), broad scope should be related to performance in a similar fashion.

Economies of scope occur when resources, fixed expenses, and learning can be shared among a broad array of products (Hill 1988). Scope economies at the business-level are possible when products are highly similar, such as men's and women's jeans (Oster 1990: 163-165). A broad product scope should increase the possibility of economies in production, distribution, marketing, and research and development (Murray 1988) even though some of the economies accruing from scale may be sacrificed (Oster 1990). Research has shown that in industrial markets breadth of product line had a small but favorable impact on costs and profits (Kekre and Srinivasan 1990). 
A firm with a broad scope may also achieve advantages from greater product availability and customer choice, especially if products are tailored to the tastes of different customers (Abell 1980; Chrisman, et al. 1988). Caves and Ghemawat (1992) have shown that product breadth increases a firm's ability to create mobility barriers from differentiation as well as improve its performance.

By contrast, the performance of narrow-scope firms centers on the benefits of specialization (Hannan and Freeman 1989). By limiting the number of product-market segments in which it competes, a firm should be able to gain superior knowledge and therefore derive competitive advantages as a consequence of an improved ability to tailor its offerings to the needs of consumers (Porter 1980).

Researchers and theorists in strategic management have struggled with the viability of narrow-scope strategies. Scholars have traditionally believed that narrow scope firms should compete only in market niches that broad-scope firms find unattractive or infeasible to enter (Buchele 1967). However, declining prospects in traditional markets may prompt large, scale-dependent firms to turn to market niches they formerly considered too small or specialized to be of interest (Penrose 1959). As large firms invade, asymmetrical mobility barriers may prevent narrow-scope firms from counter attacking the segments occupied by broad-scope rivals (Hatten and Hatten 1987).

On the other hand, some dispute the marginality of narrow-scope firms and maintain that they are capable of effective head-on competition against large, dominant rivals without the protection of market niches (Cooper, Willard, and Woo 1986). Indeed, according to Carroll (1984), the success of broad-scope firms creates conditions under which those of narrow scope may thrive.

Scope Hypothesis. Despite the advantages of specialization, the greater market power, cost advantages, and potential for market segmentation of broad scope firms suggest that, on average, they should outperform narrow-scope firms.

H1. There is a positive relationship between a firm's breadth of scope and its financial performance.

\section{The Concept of Competitive Weapons}

A firm gains competitive advantages by aligning its resources in ways that are valued by customers, and difficult for competitors to duplicate (Barney 1991). These alignments are referred to as its competitive weapons (Chrisman, et al. 1988). Porter (1980) suggested that there are two primary weapons firms can use to obtain sustainable competitive advantages: cost leadership and differentiation. He also argues that these weapons are generally incompatible and therefore the pursuit of both avenues to competitive advantage is usually unsustainable, leaving the firm "stuck-in-the-middle."

Despite Porter's reservations, the possibility of a firm deriving competitive advantages from both a low cost position and differentiation remains theoretically appealing (Chrisman, et al. 1988; Hill 1988; Murray 1988). Differentiation to create a low cost position may be possible if products are not perfectly substitutable, buyer switching costs are low, and the potential for cost reductions exist (Murray 1988). Attempts to compete with both 
weapons may not only be possible but necessary if efficiency is sustainable but imitable and differentiation opens new avenues for competitive advantages as well as further cost savings (Murray 1988). Limited empirical evidence suggests the viability of such a strategy during pronounced periods of disequilibrium (Sandberg 1986), and for firms with distinctive competence in R\&D or manufacturing (Chrisman and Boulton 1992).

By acknowledging these possibilities it becomes clear that Karnani's (1984) description of low cost and differentiation as continuums with multiplicative effects is more appropriate. His multiplicative argument suggests four distinct possibilities based on a firm's cost and differentiation positions, and clearly outlines, theoretically, the possibility of an effective combination of these weapons (Chrisman, et al. 1988). Thus, low cost firms derive competitive advantage from their low cost (and usually price) position and acceptable levels of benefits. Differentiated firms, in turn, derive competitive advantage from high levels of uniqueness offered to customers combined with acceptable cost levels. Firms with utility weapons achieve competitive advantages from both a high level of differentiation and a low delivered cost position. Finally, stuck-in-the-middle firms, being only average or below average in terms of both costs and benefits, are unable to obtain any advantages other than just "being there" (Chrisman, et al. 1988: 423). Researchers and theorists agree that failure to develop either a low cost or differentiated position leads to inferior performance (Dess and Davis 1984; Porter 1980; White 1986). Murray (1988) suggests that because of this it stands to reason that firms using both weapons simultaneously should be able to out compete rivals using only one or the other. $\mathrm{He}$ also contends that because in most markets customers will base purchasing decisions on attributes other than price, and because opportunities to exploit cost economies exist at some point of the value chain of most industries, the combination should usually be feasible. Miller (1991) asserts that utility weapons should be effective when there is no conflict between quality and low price, and when industries are relatively mature and the possibility to be distinctive in a meaningful way by either differentiation or cost leadership alone are limited. He explains that since the best ideas are imitated by competitors, a single source of competitive advantage becomes more difficult to sustain as an industry ages.

Similarly, Karnani (1984) argues that the relative effectiveness of low cost and differentiation depends upon the importance of efficiency and cross elasticity of demand. For example, in mature, concentrated industries selling heterogeneous products, low cost and differentiation should be of roughly equal importance. Product life cycle theory indicates the importance of efficiency as markets mature and demand growth slows to the level of the overall economy (Hofer and Schendel 1978; Porter 1980). On the other hand, the oligopolistic structure of a concentrated industry implies strong non-price competition, while product heterogeneity suggests the potential for differentiation based on real and perceived product and service attributes (Scherer 1970).

Competitive Weapons Hypothesis. Based on the studies discussed above, we propose that a strategy based on the use of both low cost and differentiation weapons is both a feasible and superior strategic option to the choice of one weapon alone regardless which weapon that may be. Furthermore, it has been well established that firms which fail to 
develop either a low cost or differentiation position will achieve inferior performance visa-vis firms with one of the two weapons or both. Therefore:

$\mathrm{H} 2$. There is a positive relationship between the number of competitive weapons a firm uses and its financial performance.

In other words, we predict that firms with utility weapons will outperform firms with either low cost or differentiation weapons alone. Similarly, firms with either cost or differentiation weapons will achieve performance that is statistically equivalent, but superior performance to those firms that are stuck-in-the-middle.

\section{The Relationship Between Competitive Weapons and Scope}

Up to this point we have discussed the concepts of scope and competitive weapons and speculated on their individual relationships to performance in mature, concentrated industries with heterogeneous products. However, it should be clear that these decisions cannot be made in isolation. In fact, it is the combination of decisions concerning product-market opportunities to pursue and the ways in which resources should be aligned to exploit those opportunities that constitutes a firm's business level competitive strategy (Hofer and Schendel 1978). Furthermore, it is the choices in both areas combined that determine a firm's performance, even though it is possible to investigate those choices separately in empirical research.

From the discussion provided above it should be clear that a choice of scope can reinforce or dilute the competitive advantage a firm hopes to achieve through the deployment of its resources. For example, a firm pursuing a cost advantage may be better able to achieve it by targeting a broad domain of products and markets, owing to the economies that broad scope allows. On the other hand, narrow scope might allow similar advantages, although in a more limited setting, if the firm targets highly price-sensitive customers and concentrates on products that offer cost economies independent of scale, such as those accruing from location, proprietary technologies, access to raw materials, and so on (Porter 1980). Furthermore, as companies such as General Motors have discovered, bureaucracy, excess unproductive resources, and sluggish decision making may eliminate any cost advantages accruing from size and scope. Nevertheless, while one might identify examples of successful firms pursuing any of the combinations of scope and competitive weapons we have discussed, the purpose of this study is to investigate more general patterns of the relationship between competitive strategy and performance.

Hypothesis on the Interaction of Scope and Competitive Weapons. Firms with broad scopes and utility weapons are expected to outperform firms using other strategies because a broad scope should afford greater opportunities for exploiting these weapons through economies of scale and scope, and because the dual advantages of using low cost and differentiation should provide a stronger, more enduring position vis-a-vis major competitors. On the other hand, stuck-in-the-middle firms with narrow scopes should be the lowest performers since they cannot derive either economies of scale or scope, and lack the competitive weapons necessary to build a position of specialization. Thus: 
H3. There is a positive relationship between the interaction of scope and competitive weapons and financial performance, i.e., the broader a firm's scope and the greater the number of competitive weapons used, the higher its financial performance.

It is not entirely clear, however, whether choices of scope or competitive weapons will have the greater impact on an organization's economic performance. The work of Porter (1979) implies that scope is key, whereas Hamermesh, Anderson, and Harris's research (1983) suggests the opposite. Probably closer to the truth was Sousa and Hambrick's (1989) demonstration of the importance and interactive nature of both a company's skills and an industry's key success factors, implying the importance of choices of both competitive weapons and scope at the business level. Unfortunately, Sousa and Hambrick's criteria for selecting environments were so narrow that they actually captured key success factors in industry segments rather than industries, making it difficult to draw conclusions concerning the relative importance of key success factors and skills in whole industries. Therefore, the relative importance of the environment in which firms choose to operate versus their chosen method of competing cannot be thoroughly conceived or predicted. Nevertheless, this research should provide preliminary evidence toward resolving this issue.

\section{Methodology}

Our sample included 599 business units. Data were collected and averaged for the years 1981 to 1984 , the most recent period for which data were available at the time the study was conducted. The sample was drawn from the Profit Impact of Market Strategy (PIMS) SPI4 database. The PIMS database includes self-reported data on approximately 3000 business units of large U.S. corporations. Participating companies provide more than 100 data items describing the business, its competitive environment, and its performance.

The sample was composed of firms competing in concentrated, mature industries that manufacture heterogeneous (noncommodity) products for domestic markets. The industries represented a wide variety of four-digit manufacturing industries that possessed these characteristics. Table 1 lists the industries represented in the sample.

\section{Table 1: Manufacturing Industries Represented in the Study}

\section{INDUSTRY}

Consumer Durables

Consumer Non-Durables

Capital Goods

Raw or Semi-Finished Materials

Components

Supplies

NUMBER
51
156
112
83
101
96

PERCENTAGE

$8.5 \%$
$26.0 \%$
$18.8 \%$
$13.9 \%$
$16.8 \%$
$16.0 \%$


Theoretical relevance governed our choice of industry settings. The competitive strategies and performance of firms have long been linked to industry structural variables (Hofer and Schendel 1978; Porter 1980). As a consequence, Dess, Ireland, and Hitt (1990) have argued for the need to control for industry effects in strategy research when studying multiple industries. Following Hambrick and Lei (1985), we selected industry control variables which seemed most likely to moderate the link between strategy and firm performance. Furthermore, concentration, maturity, and product heterogeneity are common in U.S. manufacturing industries (Scherer 1970). Therefore, our results are likely to be widely generalizable.

Concentrated industries were selected to ensure adequate numbers of both broad- and narrow-scope firms, and because detection of high performing narrow-scope firms in such industries would help fill theoretical and empirical gaps in the literature (White 1986). Dess, Ireland and Hitt (1990) and Hambrick and Lei (1985) agree on the importance of concentration as an industry control variable.

Mature industries were selected because most industries exist in their mature stage, the stage that generally endures for the longest period of time (Hambrick 1983). More importantly, industry maturity ensures reasonably stable relationships among the strategic and performance variables (Hofer and Schendel 1978). Industry maturity also brings strengthened relationships among operating efficiency, market share, product quality, and profitability (Anderson and Zeithaml 1984), suggesting an environment less tolerant of competitive weakness than those in early stages of industry evolution.

Heterogeneous industries were chosen because coupled with industry concentration and maturity, product heterogeneity suggests that a variety of competitive strategies might be associated with acceptable performance. The first two conditions admit the possibility of broad-scope firms using competitive weapons based on cost advantages; product heterogeneity admits the possibilities of narrow-scope and differentiation (Hill 1988).

Finally, we confined our study to domestic industries in order to minimize the effects of international competition, cross-subsidization, and variable market growth rates across countries (Sousa and Hambrick 1989).

\section{Variable Measurements}

Three sets of variables were used in the analysis to identify the scope, competitive weapons, and performance of the firms in our sample (Table 2). 
Table 2: Descriptive Statistics and Intercorrelations

INTERCORRELATIONS

FINANCIAL VARIABLE

MEAN S.D. ROI PS MS RS IS

ROI Return on Investment

22.7423 .71

SCOPE VARIABLES

PS Relative Product Breadth

$\begin{array}{llll}2.01 & .79 & .22 & -\end{array}$

MS Relative Market Breadth

$\begin{array}{llll}2.02 & .59 & .14 & .43\end{array}$

\begin{tabular}{llrrrrrrr}
\multicolumn{1}{l}{ COMPETTIVE WEAPONS VARIABLES } & & & & & & \\
RS & Receivables/Sales & 14.75 & 7.97 & .08 & -.01 & -.08 & - & \\
IS & Inventory/Sales & 19.99 & 11.32 & .34 & -.07 & -.05 & .26 & - \\
RC & Relative Compensation & 100.95 & 6.48 & .14 & .15 & .16 & -.14 & -.04 \\
RDC & Relative Direct Cost & 101.95 & 6.77 & .28 & -.17 & -.07 & .02 & .19 \\
MES & Manufacturing Expenses/Sales & 26.64 & 11.20 & .24 & -.17 & -.00 & .06 & .15 \\
RPQ & Relative Product Quality & 0.61 & 21.26 & .35 & .35 & .17 & .05 & -.11 \\
RP & Relative Price & 103.35 & 7.58 & .10 & .16 & .08 & -.03 & .01 \\
RDS & R \& D/Sales & 1.76 & 1.96 & .05 & .00 & .06 & .09 & .22 \\
AS & Advertising/Sales & 9.49 & 7.85 & .03 & -.04 & -.03 & -.03 & -.03 \\
PCG & Price Cost Gap & -1.14 & 4.38 & .08 & .02 & -.04 & -.02 & -.00 \\
II & Investment Intensity & 0.27 & 1.15 & .40 & -.05 & -.06 & .27 & .39 \\
CU & Capacity Utilization & 75.51 & 15.80 & .14 & .10 & .08 & .07 & -.06 \\
EP & Employee Productivity & 41.13 & 30.36 & .17 & .03 & .04 & -.24 & -.14
\end{tabular}

INTERCORRELATIONS

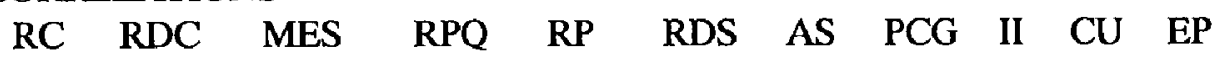
$\mathrm{RC} \quad-$

RDC $\quad .09$

$\begin{array}{lllll}\text { MES } & .04 & .12 & -\end{array}$

$\begin{array}{llll}\mathrm{RPQ} & .14 & -.15 & -.06\end{array}$

$\begin{array}{lllll}\mathrm{RP} & .19 & .24 & -.04 & .39\end{array}$

$\begin{array}{lllrrrrr}\text { RDS } & .10 & .02 & .15 & -.02 & -.01 & - & \\ \text { AS } & .05 & .06 & -.28 & -.04 & .14 & .02 & -\end{array}$

$\begin{array}{lllllllll}\text { PCG } & .10 & -.01 & -.07 & -.01 & .03 & -.07 & .07 & -\end{array}$

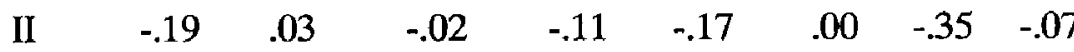

$\begin{array}{lllllllllll}\mathrm{CU} & .06 & -.21 & .06 & .12 & -.08 & -.03 & -.24 & -.05 & .10 & -\end{array}$

$\begin{array}{llllllllllll}\mathrm{EP} & .09 & .04 & -.22 & .02 & .09 & -.03 & .25 & .07 & -.08 & -.06 & -\end{array}$

Scope Variables. Scope was operationalized in terms of firms' self reports of the product and market segments in which they competed as compared to industry leaders. We classified as narrow scope the 209 firms that reported their product or market scope or 
both to be narrower than their leading competitors' and classified as broad the 390 firms that reported that their scope was equal to or broader than leading competitors on both dimensions.

Competitive Weapons Variables. Thirteen variables were used to operationalize competitive weapons. The variables used are consistent with those used in prior research on competitive strategies (Dess and Davis 1984; Hambrick 1983; Hatten 1974; Kekre and Srinivasan 1990).

Strategy scholars have warned against taxonomic classifications developed without theoretical backing (Chrisman, et al. 1988; McKelvey 1982). To avoid this problem we used prior research and theoretical arguments to predict what the characteristics of firms using different competitive weapons should be. This procedure is consistent with that of Hambrick (1983) and Sousa and Hambrick (1989), and provides a theory-based rationale to identify different types of competitive weapons. The Appendix presents the expected characteristics of each competitive weapon taxon.

The link between the theoretical groupings suggested by prior research, and the actual data was accomplished through the use of cluster analysis. Cluster analysis has been frequently used in strategy content research (Dess and Davis 1984; Hambrick 1983; Hatten 1974; Miller 1992). Harrigan (1985: 60) has stated that "cluster technir are a preferable means of sorting competitors into strategic groups because additioual interpretation of competitive dynamics is possible."

The minimum squared error grouping process (Hambrick 1983; Harrigan 1985; Miller 1992) was utilized to identify the competitive weapons of the firms. Cluster solutions were chosen so that between-group cluster distances were maximized and so that the error sum of squares increased when changing to a less optimal solution.

The best solution consisted of four clusters: cost strategies, differentiation strategies, utility strategies, and stuck-in-the-middle strategies (Table 3). The results of the four cluster solution were consistent with the classification proposed by Chrisman, et al (1988), as well as with our a priori criteria for classification. 
Table 3: Competitive Weapon Variables and Cluster Means

COMPETTTIVE WEAPONS CLUSTERS

Stuck-in-

$\begin{array}{lcrcc}\text { VARIABLES } & \text { Differentiation } & \text { Cost } & \text { Utility } & \text { the-Middle } \\ \text { Receivables/Sales } & & & & \\ \text { Inventory/Sales } & 17.2^{*} & 11.2^{*} & 7.4^{*} & 14.5^{*} \\ \text { Relative Compensation } & 22.6^{*} & 19.0^{*} & 11.0^{*} & 19.4^{*} \\ \text { Relative Direct Cost } & 102.4^{*} & 100.8^{*} & 102.8 & 100.3 \\ \text { Manufacturing Expenses/Sales } & 100.9 & 102.0^{*} & 104.4 & 102.3^{*} \\ \text { Relative Product Quality } & 26.7^{*} & 21.0^{*} & 16.2^{*} & 27.7^{*} \\ \text { Relative Price } & 24.1^{*} & -8.4^{*} & 20.6^{*} & -8.9^{*} \\ \text { R\&D/Sales } & 106.5^{*} & 101.3^{*} & 113.4 & 101.8 \\ \text { Advertising/Sales } & 1.8^{*} & 1.7^{*} & 0.6 & 1.8 \\ \text { Price-Cost Gap } & 9.0 & 14.2 & 15.9^{*} & 8.9^{*} \\ \text { Investment Intensity } & -1.2 & 0.4 & -0.3^{*} & -1.3^{*} \\ \text { Capacity Utilization } & 0.3 & 0.4^{*} & -0.7 & 0.2^{*} \\ \text { Employee Productivity } & 82.5 & 70.9 & 71.5 & 73.3 \\ & 35.5^{*} & 105.8^{*} & 144.0^{*} & 31.7^{*} \\ \text { NUMBER OF FIRMS } & 158 & & & \\ \end{array}$

* Denotes relationships between variables and competitive weapons that correspond to expectations listed in Appendix. Over 65 percent (34 of 52) of these predictions were substantiated, a result which was significantly different from $50-50$ chance $(p<.05)$.

Discriminant analysis was performed on a random sample of 75 percent of the firms to determine the reliability of the cluster solutions. The resulting discriminant function was able to classify over 90 percent of the holdout sample correctly.

Performance Variables. For the PIMS sample, performance was measured via return on investment (ROI). We did not use market-related measures of performance such as overall sales or market share because their obvious correlation with scope would have made comparisons of broad and narrow scope firms tautological.

\section{Results and Discussion}

A two-way analysis of variance (ANOVA) with an interaction term was used to test the hypotheses. Assuming a large effect size, directional hypotheses, and an alpha level of .05 , the power of the statistical analysis exceeded the traditionally accepted level of .80 (Magin, Mazen, Hemmasi, and Lewis 1987). Table 4 presents the financial performance data for the firms in the sample by scope and competitive weapons. Table 5 provides the results of the two-way ANOVA and interaction. 
Table 4: Firm Performance by Scope and Competitive Weapons

SCOPE

Broad Scope

Narrow Scope

COMPETTTIVE WEAPONS

Differentiation Weapons

Cost Weapons

Utility Weapons(Cost + Differentiation)

Stuck-in-the-Middle (No Weapons)

\section{RETURN ON INVESTMENT \\ Mean S.D. N}

$\begin{array}{lll}26.48 & 23.74 & 390 \\ 15.92 & 21.14 & 209\end{array}$

$\begin{array}{rrr}30.06 & 22.86 & 158 \\ 28.61 & 29.73 & 44 \\ 39.69 & 34.90 & 16 \\ 18.40 & 21.02 & 381\end{array}$

Table 5: ANOVA Results

\begin{tabular}{lrrrrc} 
SOURCE OF VARIATION & \multicolumn{1}{c}{ SSQ } & \multicolumn{1}{c}{ df } & \multicolumn{1}{c}{ MSQ } & \multicolumn{1}{c}{ F } & p \\
Main Effects & 32187.1 & 4 & 8046.8 & 16.4 & .000 \\
$\quad$ Scope & 10448.8 & 1 & 10448.8 & 21.3 & .000 \\
Competitive weapons & 17024.2 & 3 & 5674.7 & 11.6 & .000 \\
Two-way interaction & 5280.2 & 3 & 1760.1 & 3.6 & .014 \\
Explained & 37467.3 & 7 & 5352.5 & 10.9 & .000 \\
Residual & 289889.4 & 591 & 490.5 & & \\
Total & 327356.4 & 598 & 547.4 & &
\end{tabular}

\section{Hypothesis One}

Hypothesis one stated that there is a positive relationship between a firm's breadth of scope and its financial performance. This hypothesis was supported $(\mathrm{p}<.001)$. Although there may be benefits from focusing on a product-market niche, the general rule appears to be that a broad scope is preferable to a narrow scope.

\section{Hypothesis Two}

The second hypothesis stated that there is a positive relationship between the number of competitive weapons a firm uses and its financial performance. Thus, firms using a combination of low cost and differentiation weapons, the utility strategy, should outperform firms using only one competitive weapon. Likewise, firms that find themselves stuckin-the-middle without any clear competitive weapons should be the worst performers. This hypothesis was supported $(p<.001)$. Despite the relative scarcity of firms following a utility strategy, there was a significant, positive relationship between the number of competitive weapons utilized by the firms and their financial performance. 


\section{Hypothesis Three}

The third hypothesis stated that there is a positive relationship between the interaction of scope and competitive weapons and financial performance. In other words, we expected that firms with broad scopes using utility weapons would achieve the highest performance and stuck-in-the-middle firms with narow scopes would achieve the lowest performance. This hypothesis was supported; our analysis detected a significant interaction effect between scope and competitive weapons $(p<.02)$. Apparently, a firm's choices of scope and competitive weapons both matter and can be either mutually reinforcing or defeating depending upon which choices are made.

\section{Discussion}

Scope. We had expected broad-scope firms to outperform narrow-scope firms in the concentrated, mature industries under study. This hypothesis was confirmed. The strength of the results indicate that the market power and economies afforded by broad scope usually outweigh the benefits of specialization in such settings. Although not all firms can or should pursue a broad scope strategy, our analysis suggests the attractiveness of this option.

Competitive Weapons. Also important is the evidence of the superior performance of firms using utility weapons. While the possibility of firms competing through a combination of low cost and differentiation has been suggested (Hill 1988; Murray 1988), our results go further by demonstrating the desirability of such a strategy.

The reasons behind the success of utility strategies may be related to our decision to study mature, concentrated, manufacturing industries producing heterogeneous products. Survivors of industry shakeouts may be peculiarly suited to compete with both differentiation and low cost, or industry maturity may open new opportunities to do so (Hill 1988). Furthermore, in heterogeneous industries, perceived sources of differentiation such as advertising, or real sources of differentiation such as proprietary product features, may be necessary to obtain the sales volume required to enjoy cost economies. Likewise, concentration may provide dominant firms with both the market power and the time to develop a utility strategy, or may require narrow scope firms to seek both advantages in order to stave off threats from larger rivals.

In spite of their high performance, and consistent with previous studies (Hall 1980; White 1986), our results suggest that only a few firms are able to successfully develop utility strategies. This could be an indication that Porter (1980) was correct in assuming that the risks of attempting to achieve advantages in both cost and differentiation are higher than for attempting to develop advantages in only one area. In fact, in some industries, such as candy and perfume, there may be significant tradeoffs between low cost and differentiation that leave even a firm with a utility strategy without a clear identity amongst consumers.

The paucity of adherents to the highest performing option may partially be a consequence of our use of realized rather than intended strategies, a possibility that future studies should investigate. It seems possible, for instance, that many of the stuck-in-the-middle firms had intended to achieve both low cost and differentiation but failed on both counts. 
The imbalance found between the users of utility and stuck-in-the-middle weapons (16 versus 381) may again reflect the difficulty of attaining both low cost and differentiation, as Porter (1980) asserted. Thus, while utility weapons offer very high returns, such returns seem to come only with a substantial risk suggested, but not captured, in our methodology.

The higher number of stuck-in-the-middle firms may have also been a result of our choice of mature industries. It is possible that some firms may have lost their advantages in cost because, as experience curve effects are exhausted, a number of firms are able to reach low cost positions. Other firms may have lost advantages of differentiation because of imitation, shared knowledge, or technological development on the part of competitors. These speculations aside, other factors not accounted for in our study may hold the explanation for the relative numbers of stuck-in-the-middle firms. This is a possibility only future research can answer.

\section{Appendix: Expected Relationships Between PIMS Variables and Competitive Strategies}

\begin{tabular}{|c|c|c|c|c|}
\hline VARIABLES & Differentiation & Cost & Utility & $\begin{array}{l}\text { Stuck-in- } \\
\text { the-Middl }\end{array}$ \\
\hline Receivables/Sales & High & Low & Low & High \\
\hline Inventory/Sales & High & Low & Low & High \\
\hline Relative Compensation & High & Low & Low & High \\
\hline Relative Direct Costs & High & Low & Low & High \\
\hline Manufacturing Expenses/Sales & High & Low & Low & High \\
\hline Relative Product Quality & High & Low & High & Low \\
\hline Relative Price & High & Low & Low & High \\
\hline R\&D/Sales & High & Low & High & Low \\
\hline Advertising/Sales & High & Low & High & Low \\
\hline Price-Cost Gap & High & Low & High & Low \\
\hline Investment Intensity & Low & High & High & Low \\
\hline Capacity Utilization & Low & High & High & Low \\
\hline Employee Productivity & Low & High & High & Low \\
\hline
\end{tabular}

Receivables/Sales. A high value for this ratio implies that either the manufacturer is providing financing to its customers to differentiate its offering from competitors, or its customers have buyer power because the firm is stuck-in-the-middle (Hatten 1974; Porter 1980). Hambrick and Schecter (1983) suggest that firms emphasizing cost cutting strategies will attempt to minimize the amounts of receivables held. Firms with utility strategies are also expected to be low on this dimension, reflecting their emphasis on costs and their strong bargaining position. 
Inventory/Sales. Firms following cost strategies are expected to minimize this ratio because there is usually a cost associated with holding inventory (Hambrick and Schecter 1983). On the other hand, differentiated firms are more likely to keep high levels of inventory to provide better customer service. Utility firms are expected to resemble cost firms on this dimension for the reasons noted above. Firms stuck-in-the-middle should have a high ratio because of inefficiencies or an inability to meet sales quotas.

Relative Compensation. Because of their importance to cost structures, firms with cost or utility strategies are expected to minimize compensation expenses vis-a-vis firms with differentiation or stuck-in-the-middle strategies.

Relative Direct Costs. A cost strategy suggests low direct costs. Differentiation, on the other hand, is usually costly, as is being stuck-in-the-middle (Porter 1980). Utility firms are expected to resemble cost firms on this dimension as providing differentiation at a low cost is the essence of this strategy (Chrisman et al. 1988).

Manufacturing Expenses/Sales. Such expenses represent a substantial portion of a manufacturer's costs. Therefore, their relationship with competitive strategy should be the same as discussed above for relative direct costs (Dess and Davis 1984).

Relative Product Quality. Quality is more important to firms following differentiation and utility strategies than firms following cost strategies (Hambrick 1983). As Porter (1980) notes, firms with cost strategies will be more concerned with ensuring that the quality gap between their products and those of differentiators does not grow too large. Firms that are stuck-in-the-middle should also have lower quality, but is expected to be a consequence of ineffectiveness rather than design.

Relative Price. Because differentiation is usually costly, differentiators will usually find it necessary, if not advantageous to keep prices high. On the other hand, because firms with cost strategies have lower costs, they are more likely to compete on price (Dess and Davis 1984). Firms with utility strategies should charge lower prices for their high quality products than differentiated firms owing to their lower cost structure. Their differentiated position, however, may allow them to command price premiums vis-a-vis firms with cost strategies. Due to their high cost structures, firms stuck-in-the-middle will usually have higher prices even though they lack differentiation.

$\mathbf{R} \& D /$ Sales. Firms with differentiation or utility strategies are expected to spend substantially on R\&D to maintain a position of uniqueness (Porter 1980). Because changes in existing products or the development of new ones is often inconsistent with a low cost position, firms using cost strategies are expected to spend less on R\&D (Dess and Davis 1984; Hambrick and Schecter 1983). Stuck-in-the-middle firms will refrain from heavy R\&D investment due to a lack of resources and the long term nature of such investments. 
Advertising/Sales. Advertising is a method of achieving product differentiation (Porter 1980; Scherer 1970). Thus, firms with differentiation or utility strategies should outspend firms with cost strategies. Stuck-in-the-middle firms are expected to refrain from heavy spending on advertising for reasons similar to those listed above with respect to $R \& D$.

Price-Cost Gap. Firms that have achieved differentiation should be able to command a larger differential between their prices and costs than firms that compete on costs and prices (Caves and Ghemawat 1992). Utility firms should also have large differentials and stuck-in-the middle firms should have small differentials.

Investment Intensity. High investments in plant and equipment are often necessary to obtain low costs through economies of scale (Hatten 1974). Differentiation, on the other hand, should be more closely allied with the production of specialty and custom-designed products (Dess and Davis 1984). We expect firms with utility strategies to resemble those with a cost strategy on this dimension and stuck-in-the-middle firms to resemble differentiated firms because low cost is an essential component of the utility strategy and resource limitations or myopia inhibit large investments by firms stuck-inthe-middle.

Capacity Utilization. High capacity utilization is necessary to exploit scale economies (Hambrick 1983; Hatten 1974). Thus, CU should be higher among firms with cost or utility strategies than firms with differentiation strategies. Stuck-in-the-middle firms should also have lower capacity utilization due to a lack of a basis for sustainable advantage.

Employee Productivity. High productivity reduces labor costs per unit; thus, firms with cost or utility strategies should have higher productivity than differentiated firms (Hambrick 1983). The inefficiency and ineffectiveness of firms stuck-in-the-middle mitigates against high levels of productivity.

\section{References}

Abell, D.F. 1980. Defining the Business: The Starting Point of Strategic Planning. Englewood Cliffs, NJ: Prentice-Hall.

Anderson, C.R. and C.P. Zeithaml. 1984. "Stages of the Product Life Cycle, Business Strategy, and Business Performance." Academy of Management Journal 27: 5-24.

Barney, J. 1991. "Firm Resources and Sustained Competitive Advantages." Journal of Management 17: 99-121.

Buchele, R.B. 1967. Business Policy in Growing Firms. San Francisco, CA: Chandler Publishing.

Carroll, G. 1984. "The Specialist Strategy." California Management Review 25: 126-137. 
Capon, N., J.U. Farley, and S. Hoeing. 1990. "Determinants of Financial Performance: A MetaAnalysis." Management Science 36: 1143-1159.

Caves, R. and P. Ghemawat. 1992. "Identifying Mobility Barriers." Strategic Management Journal 13: 1-13.

Chrisman, J.J. and W.R. Boulton. 1992. "Keys to Improving Economic Performance at the Business Unit Level: Business Strategy, Functional Skills, and Key Success Factors.” Journal of Business Strategies 9: 169-190.

Chrisman, J.J., C.W. Hofer, and W.R. Boulton. 1988. "Toward a System for Classifying Business Strategies." Academy of Management Review 13: 413-428.

Cooper, A, G. Willard, and C. Woo. 1986. "Strategies for High Performing New and Small Firms." Journal of Business Venturing 1: 247-261.

Dess, G.G. and P. Davis. 1984. "Porter's (1980) Generic Strategies as Determinants of Strategic Group Membership and Organizational Performance." Academy of Management Journal 27: 467. 488.

Dess, G.G., D. Ireland, and M. Hitt. 1990. "Industry Effects and Strategic Management Research." Journal of Management 16: 7-27.

Hall, W. 1980. "Survival Strategies in a Hostile Environment." Harvard Business Review 58 (5): 75-85.

Hambrick, D.C. 1983. "High Profit Strategies in Mature Capital Goods Industries: A Contingency Approach." Academy of Management Journal 26: 687-707.

Hambrick, D.C. and D. Lei. 1985. "Toward an Empirical Prioritization of Contingency Variables for Strategy Research.” Academy of Management Journal 28: 763-788.

Hambrick, D.C. and S.M. Schecter. 1983. "Turnaround Strategies for Mature Industrial-Product Business Units." Academy of Management Journal 26: 231-248.

Hamermesh, R.G., M.J. Anderson, Jr., and J.E. Harris. 1983. "Strategies for Low Market-Share Businesses." In Strategic Management. Ed. R.G. Hamermesh. New York, NY: Wiley, 126-138.

Hannan, M.T. and J. Freeman. 1989. Organizational Ecology. Cambridge, MA: Harvard University Press.

Harrigan, K. 1985. "An Application of Clustering for Strategic Group Analysis." Strategic Management Journal 6: 55-73.

Hatten, KJ. 1974. "Strategic Models in the Brewing Industry." Unpublished Doctoral Dissertation, Purdue University. 
Hatten, K.J. and M.L. Hatten. 1987. "Strategic Groups, Asymmetrical Mobility Barriers, and Contestability." Strategic Management Journal 8: 329-342.

Hill, C. 1988. "Differentiation Versus Low Cost or Differentiation and Low Cost: A Contingency Framework." Academy of Management Review 13: 401-412.

Hofer, C.W. and D. Schendel. 1978. Strategy Formulation: Analytical Concepts. St. Paul, MN: West Publishing Company.

Kamani, A. 1984. "Generic Competitive Strategies: An Analytical Approach." Strategic Management Journal 5: 367-380.

Kekre, S. and K. Srinivasan. 1990. "Broader Product Line: A Necessity to Achieve Success." Management Science 36: 1217-1231.

Magid, A., M. Mazen, M. Hemmasi, and M.F. Lewis. 1987. "Assessment of Statistical Power in Contemporary Strategy Research.” Strategic Management Joumal 8: 403-410.

McKelvey, B. 1982. Organizational Systematics: Taxonomy, Evolution, Classification. Berkeley, CA: University of California Press.

Miller, D. 1991. "Generalists and Specialists: Two Business Strategies and their Context." In Advances in Strategic Management. Eds. P. Shrivastava, A. Huff, and J. Dutton. Greenwich, CT: JAI Press, 3-41.

Miller, D. 1992. "The Generic Strategy Trap." Journal of Business Strategy 12: 37-41.

Murray, A. 1988. “A Contingency View of Porter's Generic Strategies." Academy of Management Review 13: 390-401.

Oster, S. 1990. Modern Competitive Analysis. New York, NY: Oxford University Press.

Penrose, R. 1959. The Theory of the Growth of the Firm. New York, NY: Wiley.

Porter, M.E. 1979. "The Structure within Industries and Company Performance." Review of Economics and Statistics 61: 214-227.

Porter, M.E. 1980. Competitive Strategy. New York, NY: Free Press.

Sandberg, W.R. 1986. New Venture Performance: The Role of Strategy and Industry Structure. Lexington, MA: Lexington Books.

Scherer, F.M. 1970. Industrial Market Structure and Economic Performance. Chicago, IL: Rand MeNally. 
Sousa de Vasconcellos E Sa, J.A. and D.C. Hambrick. 1989. "Key Success Factors: Test of a General Theory in the Mature Industrial Products Sector." Strategic Management Journal 10: 367382.

White, R.E. 1986. "Generic Business Strategies, Organizational Context and Performance: An Empirical Investigation.” Strategic Management Journal 7: 217-231. 